\title{
ERRATUM
}

Silvia Bagnoli • Andrea Tedde • Elena Cellini •

Mario Rotondi · Benedetta Nacmias - Sandro Sorbi

\section{The urokinase-plasminogen activator (PLAU) gene is not associated with late onset Alzheimer's disease}

Published online: 19 March 2005

(C) Springer-Verlag 2005

\section{Neurogenetics (2004) 6:53-54}

Table 1 was omitted owing to technical problems. It is now printed below.

Table 1 PLAU P141L polymorphism: genotypes and corresponding allele frequencies in $\mathrm{AD}$ and controls

\begin{tabular}{|c|c|c|c|c|c|c|c|c|}
\hline \multirow[t]{2}{*}{ Study } & \multirow{2}{*}{$\begin{array}{l}\text { Sample/ } \\
\text { size }\end{array}$} & \multicolumn{3}{|c|}{ Genotype } & \multicolumn{2}{|c|}{ Allele } & \multicolumn{2}{|l|}{ Association } \\
\hline & & $\begin{array}{l}\text { TT } \\
\%\end{array}$ & $\begin{array}{l}\text { TC } \\
\%\end{array}$ & $\begin{array}{l}\mathrm{CC} \\
\%\end{array}$ & $\mathrm{~T} \%$ & $\mathrm{C} \%$ & Genotypic & Allelic \\
\hline \multirow[t]{2}{*}{$\begin{array}{c}\text { Bagnoli } \\
2004\end{array}$} & $\begin{array}{l}\mathrm{AD} \\
(238)\end{array}$ & 2.1 & 26 & 71.8 & 15.1 & 84.8 & $P>0.1$ & $P>0.1$ \\
\hline & $\begin{array}{l}\text { CTR } \\
(207)\end{array}$ & 2.9 & 24.1 & 72.9 & 14.9 & 85 & $\begin{array}{l}\chi^{2}=0.462 \\
2 d f\end{array}$ & $\begin{array}{c}\chi^{2}=0.00 \\
1 d f\end{array}$ \\
\hline \multirow[t]{2}{*}{$\begin{array}{l}\text { Myers } \\
2004\end{array}$} & $\begin{array}{l}\mathrm{AD} \\
(652)\end{array}$ & 7 & 46 & 73 & 24 & 76 & $P>0.1$ & $P>0.1$ \\
\hline & $\begin{array}{l}\text { CTR } \\
(824)\end{array}$ & 6 & 37 & 58 & 24 & 76 & $\begin{array}{c}x^{2}=0.1 \\
2 d f\end{array}$ & $\begin{array}{c}\chi^{2}=0.02 \\
1 d f\end{array}$ \\
\hline \multirow[t]{2}{*}{$\begin{array}{l}\text { Finckh } \\
2003\end{array}$} & $\begin{array}{l}\text { AD } \\
(347)\end{array}$ & 4 & 28.5 & 67.5 & 17.2 & 81.7 & $P>0.00039$ & $P>0.00009$ \\
\hline & $\begin{array}{l}\text { CTR } \\
(291)\end{array}$ & 7.2 & 40.6 & 52.2 & 27.4 & 72.5 & $\begin{array}{l}\chi^{2}=15.689 \\
2 d f\end{array}$ & $\begin{array}{c}\chi^{2}=15.341 ; \\
1 d f\end{array}$ \\
\hline
\end{tabular}

The online version of the original article can be found at http://dx. doi.org/10.1007/s10048-004-0203-2

S. Bagnoli $(\bowtie) \cdot$ A. Tedde $\cdot$ E. Cellini

B. Nacmias $\cdot$ S. Sorbi

Department of Neurological and Psychiatric Sciences,

University of Florence,

Viale Pieraccini 6,

50139 Florence, Italy

e-mail: bagnolis@unifi.it

Tel.: +39-055-4271379

Fax: +39-055-4271380

M. Rotondi

Department of Clinical Pathophysiology,

Unit of Endocrinology University of Florence,

Florence, Italy 